Koedoe 28: 169 (1985)

BODY MEASUREMENTS OF A FEMALE SERVAL Felis serval Schreber, 1776, FROM THE EASTERN TRANSVAAL

\title{
N. ZAMBATIS
}

Transvaal Nature Conservation Division

Hans Hoheisen Wildlife Research Station

P.O. Box 146

Hoedspruit

1380

No measurements of serval in the Transvaal Museum collection are available (Rautenbach 1982, Mammals of the Transvaal, Pretoria: Ecoplan). Smithers (1983, The Mammals of the Southern African Subregion, University of Pretoria, Pretoria), only lists measurements of serval from Zimbabwe. An opportunity to obtain measurements from an adult female serval in the Eastern Transvaal Lowveld arose when an animal trapped between two security fences at Hoedspruit $\left(24^{\circ} 16^{\prime} \mathrm{S} ; 31^{\circ} 03^{\prime} \mathrm{E}\right)$ died during an attempt to release it on 28th May 1982.

The carcass was measured and weighed one hour after death, according to the criteria of Smithers (1971, The Mammals of Bostwana, Memoir 4, National Museums of Rhodesia, Salisbury), unless otherwise defined in parentheses. The stomach was opened and was found to be empty, though the animal appeared to be in good health. Measurements (in millimetres) were as follows:

Total length

Head length

Tail length

Hind foot (including longest claw)

Shoulder height (foot pad to dorsal extremity of scapula) 580

Chest circumference (behind axilla) $\quad 360$

Neck circumference (across the axis) $\quad 200$

Ear length

Upper canine (apex to gum line) 13

Lower canine (apex to gum line) 12

Mass 